\title{
Catalytic Cyclooligomerization of Enones with Three Methylene Equivalents
}

\author{
Conner M. Farley, ${ }^{\circledR}$ You-Yun Zhou, Nishit Banka, and Christopher Uyeda*(i)
}

Department of Chemistry, Purdue University, 560 Oval Drive, West Lafayette, Indiana 47907, United States

Supporting Information

\begin{abstract}
Cyclic structures are highly represented in organic molecules, motivating a wealth of catalytic methods targeting their synthesis. Among the various ring-forming processes, cyclooligomerization reactions possess several attractive features but require addressing a unique challenge associated with controlling ring-size selectivity. Here we describe the catalytic reductive cocyclooligomerization of an enone and three carbene equivalents to generate a cyclopentane, a process that constitutes a formal $[2+1+1+1]$-cycloaddition. The reaction is promoted by a (quinox) Ni catalyst and uses $\mathrm{CH}_{2} \mathrm{Cl}_{2} / \mathrm{Zn}$ as the $\mathrm{C}_{1}$ component. Mechanistic studies are consistent with a metallacycle-based pathway, featuring sequential migratory insertions of multiple carbene equivalents to yield cycloalkanes larger than cyclopropanes.
\end{abstract}

$\mathrm{C}$ yclooligomerization reactions are a mechanistically interesting subclass of cycloadditions that currently have limited utility in organic synthesis. ${ }^{1}$ The potential value of these reactions derives from their ability to directly assemble cyclic molecules from the repeated coupling of a simple building block. However, this same feature introduces a significant challenge associated with controlling ring-size selectivity. The most prominent class of cyclooligomerization reactions involves the use of alkynes as substrates. ${ }^{2}$ Cyclotrimers are favored under most transition-metal-catalyzed conditions because of the high thermodynamic stability of benzenes relative to cyclobutadienes, cyclooctatetraenes, and higher-order annulenes. Cyclooligomerization reactions using other $\pi$-components, such as 1,3-dienes ${ }^{1,3}$ and allenes, ${ }^{4}$ have also been studied but generally exhibit poor selectivity and narrow substrate scopes.

Catalytic alkyne cyclotrimerizations are commonly initiated by an oxidative coupling reaction at a low-valent metal center to form a metallacyclopentadiene (Figure 1a). ${ }^{5}$ This intermediate then undergoes ring expansion through additional alkyne insertion events until the cyclic product is eliminated from the catalyst. In principle, a related mechanism may be accessible using a $\mathrm{C}_{1}$ component as the monomer unit (Figure $1 \mathrm{~b}$ ). For example, a $[2+2]$-cycloaddition between a $\mathrm{M}=\mathrm{CR}_{2}$ species and an alkene would likewise generate a metallacycle, in this case a saturated metallacyclobutane. The reaction would then propagate by iterative insertions of carbene equivalents and terminate by $\mathrm{C}-\mathrm{C}$ reductive elimination. Because the cycloalkane would be constructed one carbon at a time, any ring size is potentially accessible by this pathway. Here, we describe a (a) Cyclooligomerization Reactions of Alkynes

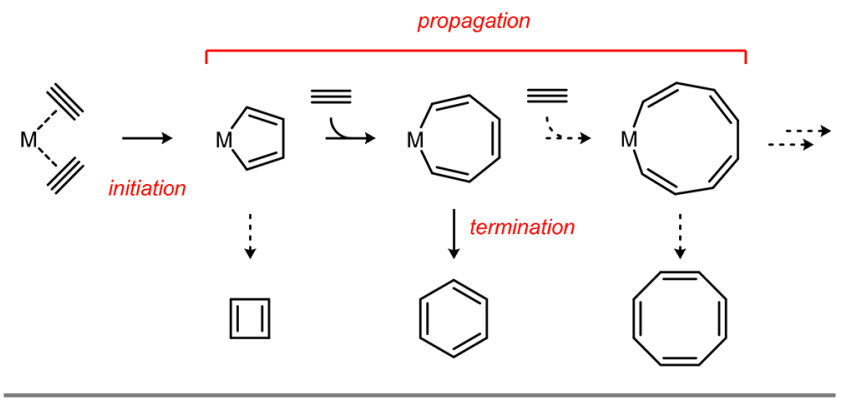

(b) A Proposed Cyclooligomerization Using a $C_{1}$ Component

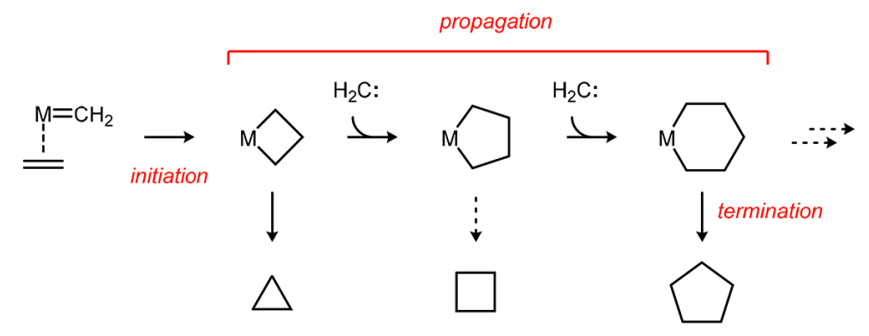

(c) $[2+1+1+1]$-Cycloaddition of Enones and Methylene

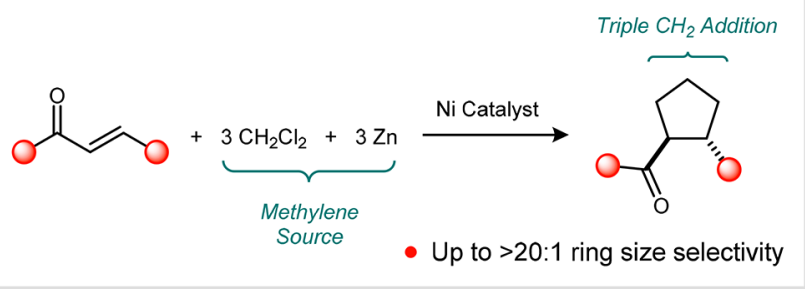

Figure 1. Cyclooligomerization strategies for the synthesis of cyclic molecules. (a) Transition-metal-catalyzed cyclotrimerization reactions of alkynes proceeding through metallacyclic intermediates. (b) A proposed cyclooligomerization reaction using a carbene as the propagating monomer. (c) A catalytic reductive $[2+1+1+1]$. cycloaddition of enones with $\mathrm{CH}_{2} \mathrm{Cl}_{2} / \mathrm{Zn}$ to generate cyclopentanes.

catalytic reductive cocyclooligomerization of an enone and three methylene equivalents to generate a cyclopentane (Figure 1c). The reaction constitutes a formal $[2+1+1+1]$-cycloaddition and uses $\mathrm{CH}_{2} \mathrm{Cl}_{2}$ as the $\mathrm{C}_{1}$ partner in combination with $\mathrm{Zn}$ metal as a stoichiometric reductant.

Received: August 3, 2018

Published: September 14, 2018 
Table 1. Effect of Catalyst Structure on Ring-Size Selectivity ${ }^{a, b}$
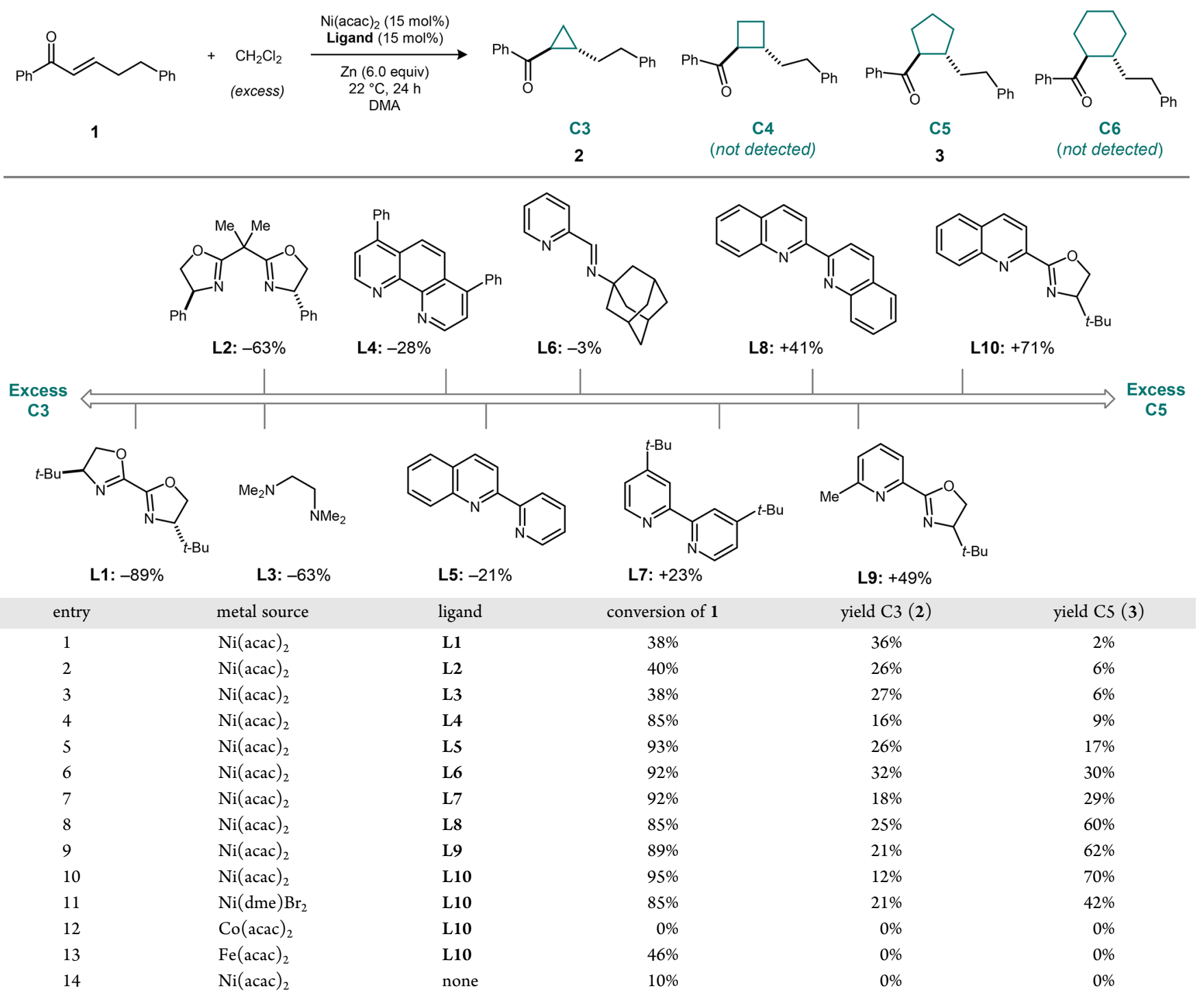

${ }^{a}$ Conversions of $\mathbf{1}$, yields of $\mathbf{2}$ (C3), and yields of $\mathbf{3}$ (C5) were determined from crude reaction mixtures by GC analysis against mesitylene as an internal standard. Reaction conditions: 1 ( $0.7 \mathrm{mmol}, 1.0$ equiv), $\mathrm{Zn}\left(6.0\right.$ equiv), metal source $\left(0.15\right.$ equiv), ligand $(0.15 \mathrm{equiv}), 1.25: 1 \mathrm{CH}_{2} \mathrm{Cl}_{2} /$ DMA $(0.3 \mathrm{~mL}) .{ }^{b}$ Selectivities for cyclopropane vs cyclopentane formation are expressed as excess values, defined as $[(\mathrm{C} 5-\mathrm{C} 3) /(\mathrm{C} 5+\mathrm{C} 3)] \times$ $100 \%$.

We discovered the reductive cyclooligomerization unexpectedly while studying transition-metal-catalyzed variants of the Simmons-Smith reaction. The key intermediates of the classical Simmons-Smith reaction are $\mathrm{Zn}$ carbenoids $\left(\mathrm{XZnCH}_{2} \mathrm{Y}\right.$ species), which are electrophilic in character and known to react preferentially with electron-rich alkenes. ${ }^{6}$ Kanai et al. observed that electron-deficient alkenes, such as enones, are also amenable to cyclopropanation under $\mathrm{CH}_{2} \mathrm{X}_{2} / \mathrm{Zn}$ conditions by the addition of $\mathrm{NiX}_{2}$ salts in catalytic loadings. ${ }^{7}$ The active carbenoid species could not be unambiguously identified but was hypothesized to be a nucleophilic $\mathrm{Ni}=\mathrm{CH}_{2}$ complex that undergoes cyclopropanation by a stepwise $[2+2]$-cycloaddition/C-C reductive elimination pathway. Studies by Grubbs, Miyashita, ${ }^{8}$ and Hillhouse ${ }^{9}$ probing the stoichiometric reactivity of $\mathrm{Ni}=\mathrm{CR}_{2}$ species and their associated nickelacyclobutanes lend credence to this proposal.

Our initial interest was in examining ligand effects in the nickel-catalyzed Simmons-Smith reaction. Accordingly, catalysts generated from $\mathrm{Ni}(\mathrm{acac})_{2}$ and nitrogen-based bidentate ligands ( $\mathbf{L} \mathbf{1}-\mathbf{L} \mathbf{1 0})$ were tested in the cyclopropanation of model enone 1 (Table 1 ). The relatively inert $\mathrm{CH}_{2} \mathrm{Cl}_{2}$ reagent was selected as the methylene source because of the absence of any background cyclopropanation using $\mathrm{Zn}$ as a stoichiometric reductant. Across the range of ligand types examined, the yield of cyclopropane 2 was found to vary significantly but never exceed $36 \%$. GC-MS analyses of the crude reaction mixtures indicated the formation of a single major byproduct with a mass corresponding to the enone (1) bearing three additional $\mathrm{CH}_{2}$ equivalents. Subsequent isolation and spectroscopic characterization of this species revealed its structure to be a transdisubstituted cyclopentane, derived from a formal reductive $[2+$ $1+1+1]$-cycloaddition process. To the extent that other cyclooligomers, such as cyclobutanes or cyclohexanes, are formed, they fall below the limits of GC-MS detection; masses corresponding to these other cyclooligomers are found in trace quantities using other enones. The ratio of cyclopropane to cyclopentane is strongly dependent on the identity of the supporting ligand. For example, $t$-Bu-Biox L1 forms cyclo- 
(a)

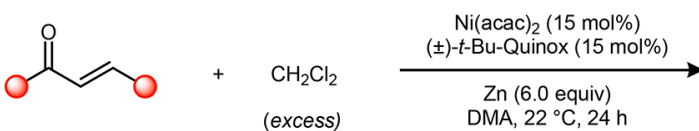

(excess)

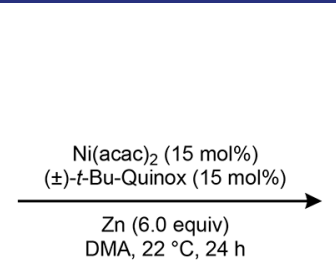

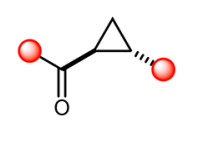

$( \pm)-\mathbf{C 3}$

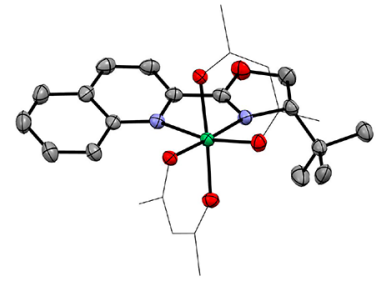

(士)-(t-Bu-Quinox $) \mathrm{Ni}(\mathrm{acac})_{2} 4$

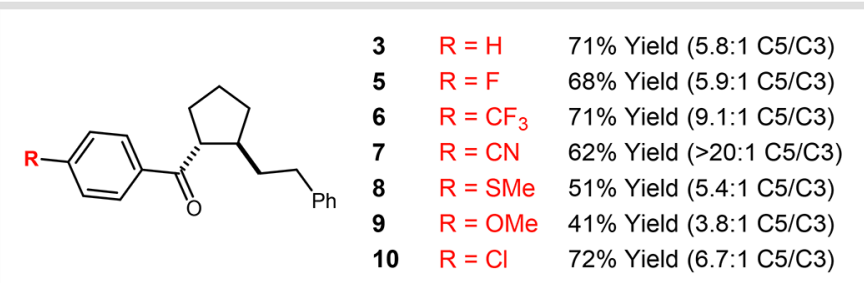

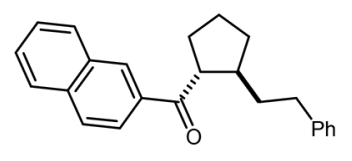

$1154 \%$ Yield (5.6:1 C5/C3)<smiles>[M]CCCCCCC1CCC[C@H]1C(=O)c1ccccc1</smiles>

$1563 \%$ Yield (6.3:1 C5/C3)<smiles>CCCCCC/C=C\CCC1CCC[C@H]1C(=O)c1ccc(F)cc1</smiles>

$1978 \%$ Yield (>20:1 C5/C3)

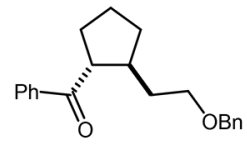

$1272 \%$ Yield (>20:1 C5/C3)

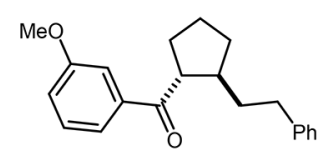

$1377 \%$ Yield (7.7:1 C5/C3)<smiles>CC(C)CC1CCC[C@@H]1C(=O)c1ccc(F)cc1</smiles>

$17 \quad 62 \%$ Yield (7.1:1 C5/C3)<smiles>CC1CCC[C@@H]1C(=O)c1ccccc1</smiles>

$2150 \%$ Yield (6.1:1 C5/C3)<smiles>O=C(c1cccc(F)c1F)[C@H]1CCCC1CCc1c[nH]c2ccccc12</smiles>

$1457 \%$ Yield (5.7:1 C5/C3)<smiles>O=C(c1ccccc1)[C@H]1CCCC1CCN1C(=O)c2ccccc2C1=O</smiles>

$18 \quad 42 \%$ Yield (2.9:1 C5/C3)

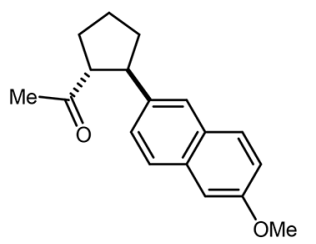

$2237 \%$ Yield (1.4:1 C5/C3)<smiles>O=C(c1ccccc1)[C@H]1CCCC1c1ccccc1</smiles>

$2345 \%$ Yield (2.2:1 C5/C3)

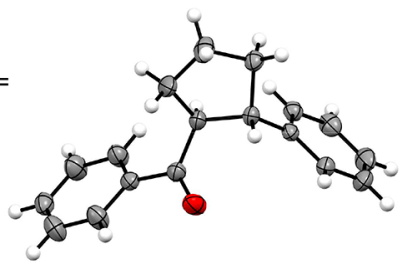

(b)<smiles>COc1ccc(C(=O)[C@@H]2CCCC2CCc2ccccc2)cc1</smiles>

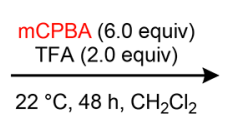<smiles>COC(=O)[C@H]1CCCC1CCc1ccccc1</smiles>
$(r r=14: 1)$<smiles>O=C(c1ccc(C(F)(F)F)cc1)[C@H]1CCCC1CCc1ccccc1</smiles>

$\underset{\text { MCPBA ( } 6.0 \text { equiv) }}{\stackrel{\text { TFA (2.0 equiv) }}{\longrightarrow}}$
$45^{\circ} \mathrm{C}, 48 \mathrm{~h}, \mathrm{CH}_{2} \mathrm{Cl}_{2}$<smiles>O=C([AlH2])O[C@H]1CCCC1CCc1ccccc1</smiles>

$2565 \%$ Yield

Figure 2. Substrate scope studies. (a) Yields are of the isolated cyclopentane following purification. C5/C3 ratios were determined from the crude reaction mixtures by ${ }^{1} \mathrm{H}$ NMR integration. Reaction conditions: enone (1.0 equiv, $\left.0.21 \mathrm{mmol}\right) ; \mathrm{Zn}$ ( 6.0 equiv); $\mathrm{Ni}(\mathrm{acac}){ }_{2}(0.15$ equiv); ( \pm )-L10 (0.15 equiv); $\mathrm{CH}_{2} \mathrm{Cl}_{2}(0.5 \mathrm{~mL})$; DMA $(0.4 \mathrm{~mL}) ; 22{ }^{\circ} \mathrm{C}, 16 \mathrm{~h}$. (b) Baeyer-Villiger oxidations of aryl cyclopentyl ketone products.

propane nearly exclusively $(2: 3=18: 1)$, whereas $t$-Bu-quinox L10 is selective for cyclopentane formation $(2: 3=1: 5.8)$.

Summarized in Figure $2 \mathrm{a}$ is the substrate scope of the nickelcatalyzed reductive cyclooligomerization reaction under conditions that were optimized for cyclopentane formation. Yields are of the isolated cyclopentane following separation from the cyclopropane byproduct. Common functional groups are tolerated, including nitriles, ethers, protected alcohols, protected amines, electron-rich heterocycles, and esters. Thioethers are susceptible to ylide formation in the Simmons-Smith reaction but are left untouched under the catalytic cyclooligomerization conditions (8). ${ }^{10}$ Likewise, aryl chlorides, which participate in 
(a)

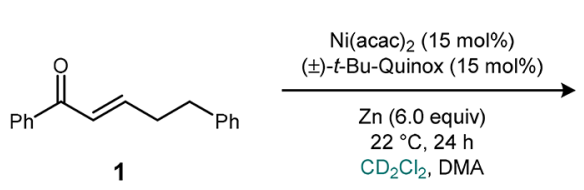

1

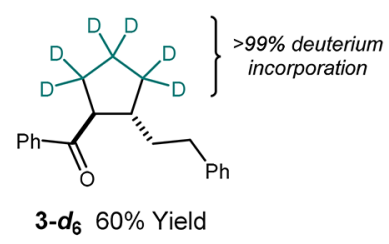

(b) (c)

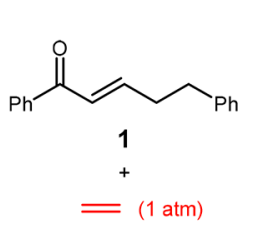

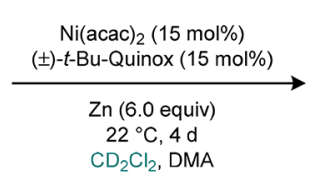

$\mathrm{CD}_{2} \mathrm{Cl}_{2}$, DMA

$\mathrm{Ni}(\mathrm{acac})_{2}(15 \mathrm{~mol} \%)$ (士)-t-Bu-Quinox (15 mo

Zn (6.0 equiv)

$22^{\circ} \mathrm{C}, 24 \mathrm{~h}$

$\mathrm{CH}_{2} \mathrm{Cl}_{2}$, DMA

(d)
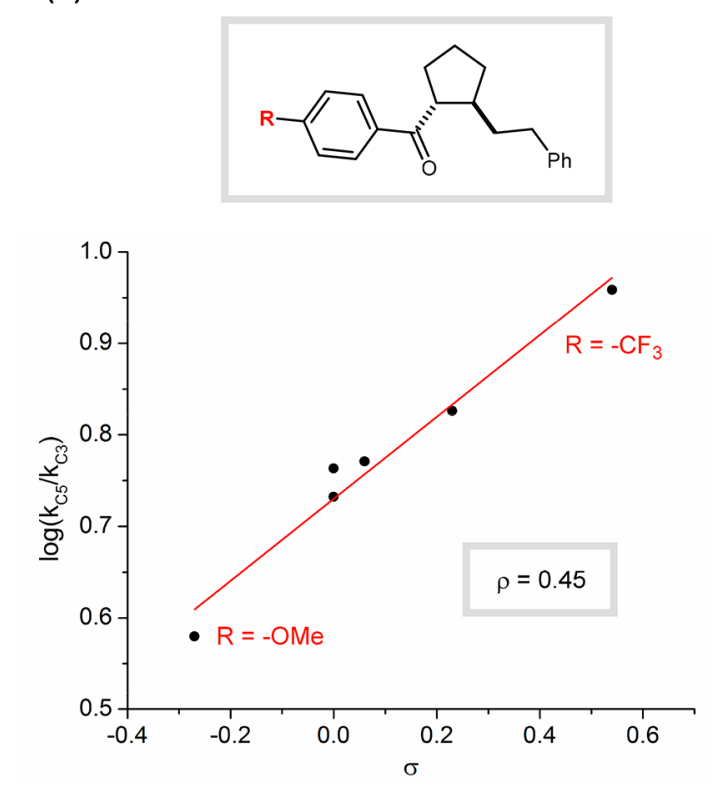

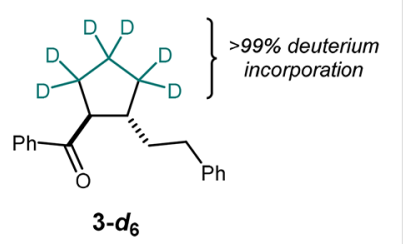<smiles>[R]/C=C\C(=O)[Al]N(C)[13CH3]</smiles>

(e) Ar
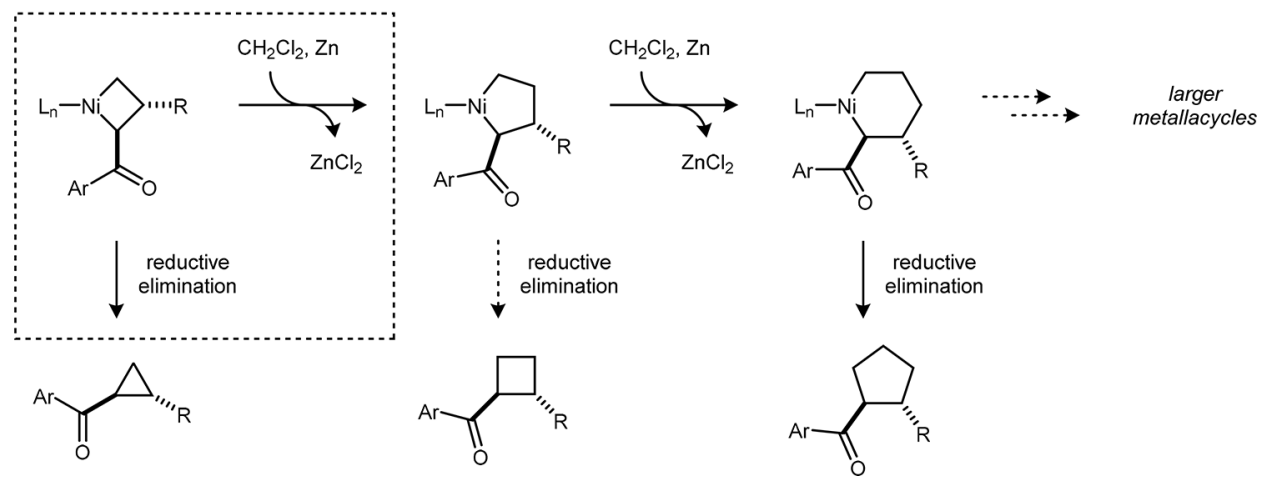

Figure 3. Mechanistic studies. (a) Experiment identifying the origin of the $-\left(\mathrm{CH}_{2}\right)_{3}-$ fragment in product 3. (b) Excluding a mechanism involving cyclopropane ring-opening. (c) Excluding a mechanism involving a coupling of enone 1 and ethylene. (d) Hammett plot of the C5/C3 selectivity vs the substituent $\sigma$ parameters. (e) A proposed cyclooligomerization mechanism involving metallacycle ring expansion. The branch point for cyclopentane vs cyclopropane formation is highlighted.

nickel-catalyzed reductive cross-coupling reactions, ${ }^{11}$ are not competitively activated. A substrate possessing two alkenes, one conjugated with a ketone and the other substituted only with alkyl groups, reacts exclusively at the electron-deficient alkene (19). The highest selectivities for cyclopentane formation were observed using substrates containing an aryl ketone and an alkyl substituent at the $\beta$-position of the alkene. For example, methyl ketone $\mathbf{2 2}$ and chalcone 23, which do not fulfill these criteria, were viable substrates for the reaction but afforded only modest selectivities for cyclopentanation $(\leq 2.2: 1)$. The product of this latter reaction (23) proved to be a crystalline solid, whose structure was assigned by X-ray diffraction analysis.

The aryl ketones present in the cyclopentanation products may be converted to other useful functional groups by the Baeyer-Villiger oxidation (Figure $2 \mathrm{~b}$ ). ${ }^{12}$ For example, 9 bearing an electron-rich 4-methoxyphenyl group is oxidized to ester $\mathbf{2 4}$ with high regioselectivity $(\mathrm{rr}=14: 1)$. The alternative regioisomeric ester is also accessible by employing the electron-deficient 4-trifluoromethyl group (25), which possesses a low migratory aptitude $(\mathrm{rr}=>20: 1)$. Upon ester hydrolysis, the former product would provide a cyclopentane carboxylic acid and the latter a cyclopentanol.
Given the unusual nature of this transformation, our first mechanistic experiment sought to confirm the origin of the $-\left(\mathrm{CH}_{2}\right)_{3}-$ fragment in product 3 (Figure $3 \mathrm{a}$ ). When the catalytic cyclopentanation of 1 was conducted using $\mathrm{CD}_{2} \mathrm{Cl}_{2}$ in the place of $\mathrm{CH}_{2} \mathrm{Cl}_{2}$, the expected $\mathrm{CD}_{2}$-incorporation was observed to form $3-d_{6}$ (60\% isolated yield). Second, a tandem cyclopropanation-ring-opening mechanism was ruled out by subjecting the separately synthesized cyclopropane 2 to the standard catalytic condition (Figure $3 \mathrm{~b}$ ). In this experiment, the cyclopropane was recovered in $>98 \%$ yield, and no conversion to cyclopentane 3 was observed. Third, we examined a potential mechanism involving the oxidative coupling of enone 1 with ethylene, which could be generated from the reductive coupling of two $\mathrm{CH}_{2} \mathrm{Cl}_{2}$ equivalents (Figure 3c). Miyashita previously observed the formation of ethylene from the dimerization of a proposed transient $\mathrm{Ni}=\mathrm{CH}_{2}$ species. ${ }^{8 \mathrm{~b}}$ Furthermore, ethylene is known to undergo nickel-mediated oxidative coupling reactions with electron-deficient $\pi$-systems. ${ }^{13}$ The catalytic cyclopentanation of enone 1 was carried out using labeled $\mathrm{CD}_{2} \mathrm{Cl}_{2}$ under an atmosphere of nondeuterated ethylene gas. The presence of ethylene was found to inhibit the rate of cyclopentanation, but product $3-d_{6}$ was nonetheless obtained in fully deuterium- 
labeled form. This result suggests that either ethylene is not an intermediate in the reaction or that it is generated but remains tightly bound to $\mathrm{Ni}$ and thus cannot exchange with free ethylene.

Finally, during our substrate scope studies, we noted a pronounced dependence of the selectivity for cyclopropane versus cyclopentane formation on the electronic properties of the aryl ketone (Figure 3d). For a series of 4-substituted aryl enones (3, 5-10), there is a linear relation between the selectivity values $(\mathrm{C} 5 / \mathrm{C} 3)$ and the substituent $\sigma$ parameters $(\rho$ $=0.45) .{ }^{14}$ Electron-withdrawing substituents result in the highest selectivities for cyclopentane formation. One possible interpretation of this trend is in the context of the metallacyclebased mechanism proposed by Kanai. In this pathway, the selectivity for cyclopropanation versus cyclooligomerization would be governed by the relative rates of reductive elimination (termination) and carbene insertion (propagation). Carboncarbon reductive elimination reactions are known to be accelerated by the presence of an electron-donating group conjugated to one of the carbons undergoing bond formation; electron-donating groups generally destabilize $\mathrm{M}-\mathrm{C}$ bonds to a greater extent than the product $\mathrm{C}-\mathrm{C}$ bond. ${ }^{15}$ On the other hand, the carbene insertion step would likely be insensitive to the electronic properties of the aryl group. Previous kinetics studies have shown that $\mathrm{CO}$ migratory insertion reactions occur preferentially at more electron-rich $\mathrm{M}-\mathrm{C}$ bonds. ${ }^{16}$ The analogous process in the reductive cyclooligomerization would therefore favor carbene insertion into the $\mathrm{Ni}-$ alkyl over the $\mathrm{Ni}-$ enolate bond such that the aryl group would exert only an indirect effect on the rate of this step.

In summary, zinc carbenoid additions to alkenes have been extensively studied since the seminal work of Emschwiller, ${ }^{17}$ Simmons, and Smith. ${ }^{18}$ However, in no cases have these reactions been observed to access pathways that lead to multiple $\mathrm{CH}_{2}$ addition, presumably because of the concerted nature of the carbene-transfer mechanism. In this context, transitionmetal-bound carbenes are attractive as alternative $\mathrm{CH}_{2}$ transfer agents because of their potential to react through stepwise organometallic pathways. By intercepting transient metallacyclic intermediates prior to $\mathrm{C}-\mathrm{C}$ reductive elimination, it is possible to develop new transformations that form ring systems other than cyclopropanes. This strategy is demonstrated here in the context of a nickel-catalyzed $[2+1+1+1]$-cycloaddition of enones using three methylene equivalents derived from $\mathrm{CH}_{2} \mathrm{Cl}_{2}$ and six reducing equivalents supplied by $\mathrm{Zn}$ metal. Together, these results point to opportunities for the development of other multicomponent cycloaddition reactions using reductively generated $\mathrm{CH}_{2}$ as a $\mathrm{C}_{1}$ partner.

\section{ASSOCIATED CONTENT}

\section{S Supporting Information}

The Supporting Information is available free of charge on the ACS Publications website at DOI: 10.1021/jacs.8b08296.

Experimental procedures and characterization data (PDF)

$\mathrm{C}_{18} \mathrm{H}_{18} \mathrm{O}$ X-ray crystallography data (CIF)

$\mathrm{C}_{59} \mathrm{H}_{72} \mathrm{~N}_{4} \mathrm{Ni}_{2} \mathrm{O}_{10} \mathrm{X}$-ray crystallography data (CIF)

\section{AUTHOR INFORMATION}

Corresponding Author

*cuyeda@purdue.edu

ORCID

Conner M. Farley: 0000-0002-4067-0848
Christopher Uyeda: 0000-0001-9396-915X

\section{Notes}

The authors declare no competing financial interest.

\section{ACKNOWLEDGMENTS}

This research was supported by the NIH (R35 GM124791). Xray diffraction data were collected using an instrument funded by the NSF (CHE-1625543). We thank Matthias Zeller for assistance with X-ray crystallography. C.U. is an Alfred. P. Sloan Foundation Research Fellow.

\section{REFERENCES}

(1) (a) Wilke, G. Angew. Chem., Int. Ed. 1963, 2, 105-115. (b) Heimbach, P. Angew. Chem., Int. Ed. Engl. 1973, 12, 975-989. (c) Saito, S. In Modern Organonickel Chemistry; Tamaru, Y., Ed.; WileyVCH: Weinheim, 2005.

(2) (a) Reppe, W.; Schweckendiek, W. Justus Liebigs Ann. Chem. 1948, 560, 104-116. (b) Vollhardt, K. P. C. Angew. Chem., Int. Ed. Engl. 1984, 23, 539-556. (c) Schore, N. E. Chem. Rev. 1988, 88, 1081-1119. (d) Saito, S.; Yamamoto, Y. Chem. Rev. 2000, 100, 2901-2916. (e) Agenet, N.; Buisine, O.; Slowinski, F.; Gandon, V.; Aubert, C.; Malacria, M. Org. React. 2007, 68, 1-302.

(3) Müller, H.; Wittenberg, D.; Seibt, H.; Scharf, E. Angew. Chem., Int. Ed. Engl. 1965, 4, 327-332.

(4) (a) Benson, R. E.; Lindsey, R. V. J. Am. Chem. Soc. 1959, 81, 42474250. (b) De Pasquale, R. J. J. Organomet. Chem. 1971, 32, 381-393. (c) Englert, M.; Jolly, P. W.; Wilke, G. Angew. Chem. 1971, 83, 84-85. (d) Otsuka, S.; Nakamura, A.; Yamagata, T.; Tani, K. J. Am. Chem. Soc. 1972, 94, 1037-1038.

(5) (a) Whitesides, G. M.; Ehmann, W. J. J. Am. Chem. Soc. 1969, 91, 3800-3807. (b) Hardesty, J. H.; Koerner, J. B.; Albright, T. A.; Lee, G.Y. J. Am. Chem. Soc. 1999, 121, 6055-6067. (c) Agenet, N.; Gandon, V.; Vollhardt, K. P. C.; Malacria, M.; Aubert, C. J. Am. Chem. Soc. 2007, 129, 8860-8871.

(6) Boche, G.; Lohrenz, J. C. W. Chem. Rev. 2001, 101, 697-756.

(7) (a) Hiroyoshi, K.; Nobuyuki, H. Chem. Lett. 1979, 8, 761-762. (b) Kanai, H.; Hiraki, N.; Iida, S. Bull. Chem. Soc. Jpn. 1983, 56, 10251029. (c) Hiroyoshi, K.; Yoshimasa, N.; Hideki, M. Bull. Chem. Soc. Jpn. 1983, 56, 1592-1597.

(8) (a) Grubbs, R. H.; Miyashita, A. J. Am. Chem. Soc. 1978, 100, 7418-7420. (b) Miyashita, A.; Ohyoshi, M.; Shitara, H.; Nohira, H. J. Organomet. Chem. 1980, 338, 103-111. (c) Miyashita, A.; Grubbs, R. H. Tetrahedron Lett. 1981, 22, 1255-1256.

(9) (a) Mindiola, D. J.; Hillhouse, G. L. J. Am. Chem. Soc. 2002, 124, 9976-9977. (b) Waterman, R.; Hillhouse, G. L. J. Am. Chem. Soc. 2003, 125, 13350-13351.

(10) Kosarych, Z.; Cohen, T. Tetrahedron Lett. 1982, 23, 3019-3022.

(11) (a) Everson, D. A.; Jones, B. A.; Weix, D. J. J. Am. Chem. Soc. 2012, 134, 6146-6159. (b) Weix, D. J. Acc. Chem. Res. 2015, 48, 17671775.

(12) Amador, A. G.; Sherbrook, E. M.; Yoon, T. P. J. Am. Chem. Soc. 2016, 138, 4722-4725.

(13) (a) Hoberg, H.; Peres, Y.; Krüger, C.; Tsay, Y.-H. Angew. Chem., Int. Ed. Engl. 1987, 26, 771-773. (b) Ogoshi, S.; Haba, T.; Ohashi, M. J. Am. Chem. Soc. 2009, 131, 10350-10351.

(14) Hansch, C.; Leo, A.; Taft, R. W. Chem. Rev. 1991, 91, 165-195.

(15) Hartwig, J. F. Inorg. Chem. 2007, 46, 1936-1947.

(16) Alexander, J. J. In The Metal-Carbon Bond. Hartley, Fr., Patai, S., Eds.; Wiley: New York, 1985.

(17) Emschwiller, G. Compt. Rend. 1929, 188, 1555-1557.

(18) (a) Simmons, H. E.; Smith, R. D. J. Am. Chem. Soc. 1959, 81, 4256-4264. (b) Charette, A. B.; Beauchemin, A. Org. React. 2001, 58, $1-415$. 